\title{
A review of engineering dielectric properties of nanocomposites through effectively removed interfacial
}

Article

Accepted Version

Rahim, N.H., Lau, K.Y., Tan, C.W., Ching, K. Y. and Vaughan, A.S. (2021) A review of engineering dielectric properties of nanocomposites through effectively removed interfacial. IEEE Transactions on Dielectrics and Electrical Insulation, 28 (2). pp. 448-459. ISSN 1070-9878 doi:

https://doi.org/10.1109/TDEI.2020.009200 Available at https://centaur.reading.ac.uk/102032/

It is advisable to refer to the publisher's version if you intend to cite from the work. See Guidance on citing.

To link to this article DOI: http://dx.doi.org/10.1109/TDEI.2020.009200

Publisher: IEEE

All outputs in CentAUR are protected by Intellectual Property Rights law, including copyright law. Copyright and IPR is retained by the creators or other copyright holders. Terms and conditions for use of this material are defined in the End User Agreement. 


\section{CentAUR}

Central Archive at the University of Reading

Reading's research outputs online 


\title{
A Review of Engineering Dielectric Properties of Nanocomposites through Effectively Removed Interfacial Water
}

\author{
N. H. Rahim ${ }^{1,}$, K. Y. Lau ${ }^{1}$, C. W. Tan ${ }^{1}$, K. Y. Ching ${ }^{3}$ and A. S. Vaughan ${ }^{4}$ \\ ${ }^{1}$ School of Electrical Engineering, Universiti Teknologi Malaysia, Johor Bahru 81310, Malaysia \\ ${ }^{2}$ Faculty of Electrical Engineering, Universiti Teknikal Malaysia Melaka, Hang Tuah Jaya 76100, Malaysia \\ ${ }^{3}$ School of Foundation, University of Reading Malaysia, Iskandar Puteri 79200, Malaysia \\ ${ }^{4}$ Electronics and Computer Science, University of Southampton, Southampton SO17 1BJ, UK
}

\begin{abstract}
The current work reviews the importance of engineering the interface between nanofillers and polymers to achieve unique dielectric properties in nanocomposites. Although many improved dielectric properties of nanocomposites have been attributed to the presence of the interface, the interface can also be an attractive location for water to accumulate, which may otherwise jeopardize the dielectric properties of nanocomposites. Consequently, the use of surface functionalization and calcination techniques in removing water-related moieties on nanofillers is highlighted. Specifically, the effects of nanofiller calcination on two exemplar oxide-based nanocomposite systems, namely, silica-based nanocomposites and zirconia-based nanocomposites, are discussed. Evidence suggests that nanofiller calcination influences not only the water-related chemistry, but also the structure of oxidebased nanofillers. Significantly, for detailed interfacial chemistry of nanofillers to become relevant in engineering the dielectric properties of nanocomposites, effective removal of interfacial water on nanofillers is crucial.
\end{abstract}

Index Terms - nanocomposites, interface, water, calcination, dielectric, silica, zirconia

\section{INTRODUCTION}

IN electrical power engineering, electrical insulation is vital to ensure the safe and reliable operation of high voltage equipment. Nowadays, polymers are widely used in this application, due to their good dielectric properties, low cost, low weight and ease of production. Significantly, for all insulating materials, electrical breakdown strength is a major factor, that will influence the utility of the material [1].

The development of polymeric insulation technology began as early as the 1910s. In the early stage of cable development, poly(vinyl chlorine) (PVC) was commonly used [2]. With the discovery of polyethylene (PE), cable manufacturers shifted to the use of PE, due to its desirable properties, such as lower permittivity and higher breakdown strength compared to PVC [3]. Later, in 1955, crosslinked polyethylene (XLPE) was introduced, where XLPE yielded many of the same benefits as $\mathrm{PE}$, but with additional advantages with regard to aging stability and thermal resistance. Up until today, XLPE has remained the polymeric material of choice for use in many high voltage cable applications.

Manuscript received on 30 June 2020, in final form xx Month 20yy, accepted xx Month 20yy. Corresponding author: K. Y. Lau.
Recently, polymer nanocomposites have attracted many researchers' attention in the field of dielectrics and electrical insulation $[4,5]$. The use of polymer nanocomposites was initiated in the early 1990s, when the potential property improvements that could result from the incorporation of nanometer-sized inclusions were anticipated by Lewis [6]. This led to the concept of "nanometric dielectrics" - nowadays widely referred to as nanodielectrics [7, 8]. This class of material exhibits unique properties, even with the addition of nanofillers at low loadings (less than $10 \mathrm{wt} \%$ ). This is in marked contrast to conventional microcomposite materials, which commonly involve filler loading levels in excess of $50 \mathrm{wt} \%$. The nanoscopic feature of nanocomposites therefore allows the dielectric processes of the materials to occur at a nanoscale level. Consequently, dielectric improvements in nanocomposites are unique and have been reported to span a wide range of high voltage insulation properties, such as improved breakdown strength, enhanced partial discharge resistance, reduced space charge formation, and lowered dielectric loss, especially when compared to microcomposites [9].

The following sections of this paper are arranged as follows. First, the evolving topic of interfaces is considered from the perspective of local interactions, consequent changes in structure and how such material modifications influence the macroscopic properties of nanodielectrics. The following section then considers how such interfaces may, additionally, 
constitute regions for accumulation of impurities and, in particular, absorbed water. Finally, potential mitigation strategies are discussed.

\section{INTERFACES IN NANOCOMPOSITES}

Many experimental findings on nanometer-sized fillers as additives for polymers imply a promising future for such material systems with, in many cases, outstanding performance being reported through the addition of just a few weight percent of nanofiller. This has mainly been attributed to properly engineered interfaces between the base polymer and the nanofiller (as shown in Figure 1), which in turn, influence the bulk electrical performance of the resulting dielectric material. Since the specific interfacial area between the filler and the matrix is extremely large in nanocomposites compared to conventional microcomposites, improvements in insulating performance are expected to be realized through appropriate control of the consequent local factors: i.e. through nanotechnology.

There are many proposed models relating to interfaces within nanocomposites and, in the field of nanodielectrics, of particular note is Lewis' interface model [6]. This considers the variation in the intensity, $I$, of some quantity on moving from the bulk of phase A (characterized by its relevant macroscopic value, $I_{A}$ ) through an interfacial region, into the bulk of phase $\mathrm{B}$ (characterized by its relevant macroscopic value, $I_{B}$ ). Where $I$ varies monotonically across the interface from $I_{A}$ to $I_{B}$, the overall intensity of the composite system, $I_{C}$, is such that its value falls between $I_{A}$ and $I_{B}$. Conversely, where the spatial variation is not monotonic - and particularly where the specific interfacial area is large, as for nanofillers $-I_{C}$ may not be intermediate between $I_{A}$ and $I_{B}$. That is, the nanodielectric may exhibit a level of performance that exceeds that of both phase A and phase B. In addition, Lewis' ideas also invoke concepts derived from colloid science, whereby Stern and GouyChapman diffuse double layers exist near the interface between the filler and the polymer [10].

Elsewhere, the above general concept has been given specific structural interpretations, as in the multi-core model proposed by Tanaka et al [11]. In this, it is suggested that three interfacial layers, or interphases, may exist surrounding a nanoparticle: the first layer (the bonded layer), the second layer (the bound layer), and the third layer (the loose layer). The Gouy-Chapman diffuse layer (the fourth layer), additionally, overlaps these three layers, with charge decaying exponentially beyond the initial three layers, causing a cooperative effect with neighboring nanoparticles.

Many other, similar, interphase models have also been proposed to explain the means by which internal interfaces affect the dielectric performance of nanocomposites. For example, Li et al [12] suggested the multi-region structure model, while Singha and Thomas [13] proposed the dual-layer model. These proposed models assume that nanoparticle/ polymer interactions lead to the formation of two interfacial layers outside each nanoparticle. Meanwhile, Raetzke et al [14] and Daily et al [15] suggested the presence of a single interphase layer within nanocomposites. A brief overview of

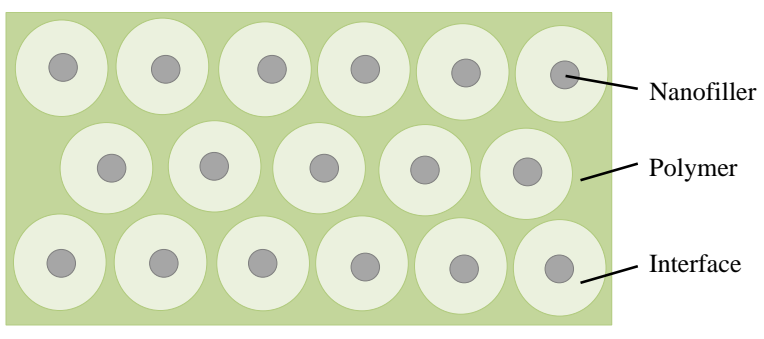

Figure 1. The interface between spherical particles and polymer.

these different concepts can be found in the work of Lau et al [5].

A common feature of the ideas summarized above is that the modified region lies in the matrix surrounding the disperse nano-phase. However, alternative and complementary concepts have recently begun to emerge in the nanodielectrics field, namely, the potential role of interfacial regions located within each nanoparticle. For example, Tanaka's dielectric quantum dot model [16] considers nanofillers in terms of a core plus one or more shell layers, which differ in terms of factors such as the local density of states. Similar ideas have been presented elsewhere [17], where the surface regions of nanoparticles were suggested to contain a high concentration of defects (e.g. foreign atoms, geometrical irregularities, coordinative unsaturation, etc.), which would equate to localized energy levels that would not be present in the ideal, bulk structure.

Overall, the presence of interfaces within nanocomposites has frequently been claimed to be the critical factor that affects the dielectric properties of such materials and, therefore, it is essential to ensure the interfacial quality of the prepared materials through proper sample preparation techniques [18]. The significance of the interface in polymer nanocomposites was stressed in 1994 by Lewis [6], where the use of nanocomposites with a properly engineered interface will potentially enhance breakdown performances [19-21].

According to Wang et al [22], the addition of nanometersized silicon dioxide $\left(\mathrm{SiO}_{2}\right)$ to low density polyethylene (LDPE) resulted in breakdown strength improvements in $\mathrm{LDPE} / \mathrm{SiO}_{2}$ nanocomposites. For example, an improvement in $\mathrm{AC}$ breakdown strength was found at $0.5 \mathrm{wt} \%$ of $\mathrm{SiO}_{2}$ loading level compared to unfilled LDPE. Furthermore, improved DC breakdown strength was also recorded at the $1 \mathrm{wt} \% \quad \mathrm{SiO}_{2}$ loading level. These improvements were attributed to successfully engineered interfaces within the nanocomposites, as a consequence of surface modification of $\mathrm{SiO}_{2}$ through the use of a silane coupling agent.

Tsekmes et al [23] also found that improvements in the electrical and thermal properties of epoxy nanocomposites could be achieved by adding a small amount of a surfacemodified boron nitride (BN) nanofiller; improvements in $\mathrm{AC}$ and DC breakdown strength and thermal conductivity were reported. By surface modification of their BN, excellent adhesion between the base polymer and the nanofiller was claimed. Moreover, due to the presence of interfacial layers, an enhancement in the interphase was inferred between the base polymer and the nanofiller. Therefore, the interface between the base polymer and nanofiller has a significant influence on the dielectric properties of nanocomposite insulation materials. 
Subsequently, we consider such effects and their influence on charge transport before, finally, considering potential strategies for material modification - in particular, we review thermal processing as a means of modifying both the surface chemistry and internal structure of nanoparticles in the context of two exemplar systems.

\section{INTERFACIAL WATER ISSUES}

To date, the incorporation of nanoparticles into polymers has not always improved the breakdown strength of the system, implying that there might be as yet unidentified factors that jeopardize the breakdown performance, as a consequence of nano-inclusion [24-26]. Although it is certain that the addition of nanoparticles to polymers affects dielectric properties (beneficially or adversely), the extent to which the various reported effects are related directly to the presence of the nanoparticles themselves, or are influenced by secondary factors associated with the preparation of nanocomposites is unclear. For example: nanoparticles can act as nucleation sites, affecting the morphology of surrounding semicrystalline matrix polymers; many processing protocols involve solvents, ionic stabilization, etc., such that the intended incorporation of nanoparticles may be accompanied by the unintended introduction of impurities; water is ubiquitous in the environment and the interface between the base polymer and nanofiller can be a thermodynamically attractive place for water to accumulate. Indeed, water is often found to surround nanofillers, forming a hydrated shell, as illustrated in Zou et al's water shell model [27]. From this, the thickness of the water shell is related to the extent of hydration, such that the overall level of hydration depends on the loading level of the nanofiller. Figure 2 illustrates how interfacial water can be present at nanocomposites interfaces.

A significant factor that contributes to water uptake in nanocomposites is the nanofiller itself and, specifically, the interaction thermodynamics with the polar water molecule. For example, in the case of hexagonal $\mathrm{BN}$, the trivalent nature of both boron and nitrogen is fully satisfied through the hexagonal crystallography of each layer. In contrast, the tetravalent nature of silicon can lead to a range of surface structures in the case of $\mathrm{SiO}_{2}$. Bonding in silica is based upon covalent $\mathrm{Si}-\mathrm{O}-\mathrm{Si}$ linkages such that, within the bulk of a perfect quartz crystal, each silicon atom is surrounded by a tetrahedral arrangement of four such disilyl ether bridges. In less ideal circumstances, such as at the surface of an amorphous silica nanoparticle, less ideal arrangements occur, which have been characterized in terms of the local bonding. Silicon atoms ideally bonded to four other silicon atoms through disilyl ether bridges are termed $\mathrm{Q}^{4}$ (see Figure 3a); silicon atoms bonded to three other silicon atoms in this way and to one other moiety are termed $\mathrm{Q}^{3}$ (see Figure $3 \mathrm{~b}$ ), etc. In terms of $\mathrm{Q}^{3}$ conformations, for example, the fourth nondisilyl ether linkage commonly involves hydroxyl (silanol) groups which, being polar, readily hydrogen bonds to water [28-31].

According to Zou et al [27], the addition of a $\mathrm{SiO}_{2}$ nanofiller into an epoxy resin resulted in high water absorption in the resulting epoxy $/ \mathrm{SiO}_{2}$ nanocomposites, compared to the unfilled epoxy. Additionally, enhanced mobility of charge carriers was

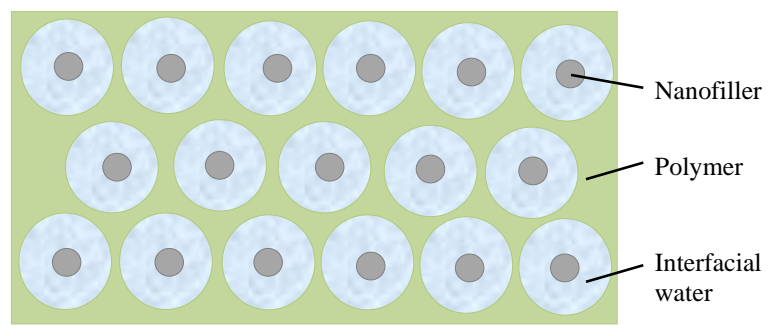

Figure 2. The interface as in Figure 1, but with water residing at the interface.

(a)

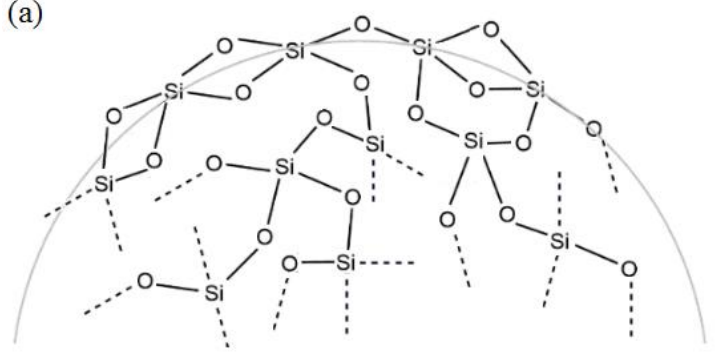

(b)

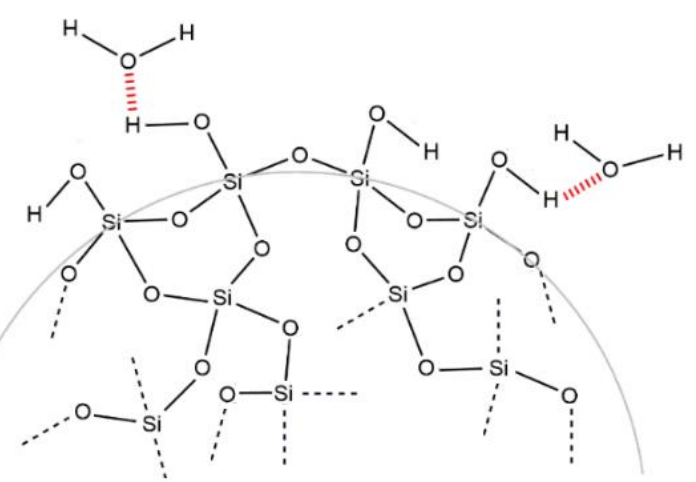

Figure 3. Surface of $\mathrm{SiO}_{2}$ with (a) $\mathrm{Q}^{4}$ conformations, (b) $\mathrm{Q}^{3}$ conformations.

reported when the absorbed level of water exceeded some critical level, presumably, as a result of overlap of neighboring nanoparticle hydration shells. This overlap phenomenon was exacerbated by high loading levels of nanofiller (i.e. reduced inter-particle separation). Meanwhile, Zhang and Stevens [28] compared the dielectric effect of absorbed water in an epoxy resin and an epoxy/alumina nanocomposites and reported that loss peaks associated with the absorbed water in the unfilled and nanofilled epoxy appeared at different frequencies and exhibited different dynamics. This behavior was attributed to the interplay between interfacial water mobility and bonding at the interface. Similar observations were reported for $\mathrm{PE} /$ alumina nanocomposites [28] and $\mathrm{PE} / \mathrm{SiO}_{2}$ nanocomposites [29].

Elsewhere, Lau et al [30] reported that the existence of water in nanocomposites, especially those containing oxide-based nanofillers, is critical and requires careful consideration, since such water-related phenomena can lead to degraded dielectric performance, especially in high voltage applications. For example, moisture adsorption onto nanofiller surfaces has been shown to lead to increased electrical conductivity and a reduction in direct current (DC) breakdown strength [31-35]. In addition, it has been reported $[36,37]$ that the dielectric loss 
tangent increases with increasing moisture in nanocomposites. Meanwhile, Praeger et al [38] also reported that a major factor that affects the breakdown strength, conductivity, dielectric response, and space charge is the water content of nanocomposites. Furthermore, when the filler content increased, the aforementioned effects become much more pronounced [26, 36, 37, 39, 40].

Significantly, the dielectric behavior of nanocomposites depends on interfaces within nanocomposites, which in turn are closely related to the water adsorption characteristics of the nanoparticles. Indeed, the available literature [31, 32, 41, 42] shows that oxide-based nanofillers, in particular, adsorbed a significant amount of water even when stored under ambient conditions; this suggests that water is readily partitioned to polar surfaces. Although detailed analysis of the water-related chemistry and structure of oxide-based nanofillers would be beneficial, it is not possible to provide truly comprehensive data sets and a complete analysis of all possible issues here. Consequently, for additional information concerning key factors such as water-related chemistry and the structure of oxide-based nanofillers, reference to the following publications is recommended [36, 40, 43, 44-48].

\section{INTERFACIAL CHARGE TRAPPING}

When polymers are used as the insulation in high voltage cables, dielectric properties such as electrical conductivity and breakdown strength can deteriorate over time, due to various factors, including the presence of water [49]. In the preceding section, based on the nanocomposite study of Zou et al [27], the mobility of charge carriers was found to increase as the absorbed level of water increased. This suggests that the degradation process caused by water is closely related to the trapping processes of charge carriers, which can occur under different trap conditions such as shallow traps, an increased number of traps, and deep traps. This is briefly illustrated in Figure 4. Under these different trap conditions, the energy required for a charge to move from point $A$ to point $B$ (representing charge mobility) becomes different.

For appropriately designed nanocomposites, their enhanced breakdown strength may be a consequence of an effective reduction in the mobility of excess (injected) electrons, as a result of additional trapping processes at the new interfaces created by the presence of the included nanoparticles, which supplement the traps already present in the base polymer (e.g. through nanovoids, structural discontinuities, chemical defects, impurities, etc.) $[50,51]$. Indeed, previous work by Lau et al [52] on $\mathrm{PE} / \mathrm{SiO}_{2}$ nanocomposites suggested that space charge limited conduction occurs in nanocomposites, with the absorption current behavior of the investigated nanocomposites being very different from that of the reference, unfilled PE (see Figure 5). While the current flowing through the unfilled PE decreased with time in a conventional manner, all the nanocomposites exhibited an initial decrease, followed by a period in which the current increased with increasing time of electric field application. This was considered in terms of three phases, related to different charge trapping mechanisms within the nanocomposites as a consequence of the presence of nanofiller/polymer interfaces. Specifically, during the first
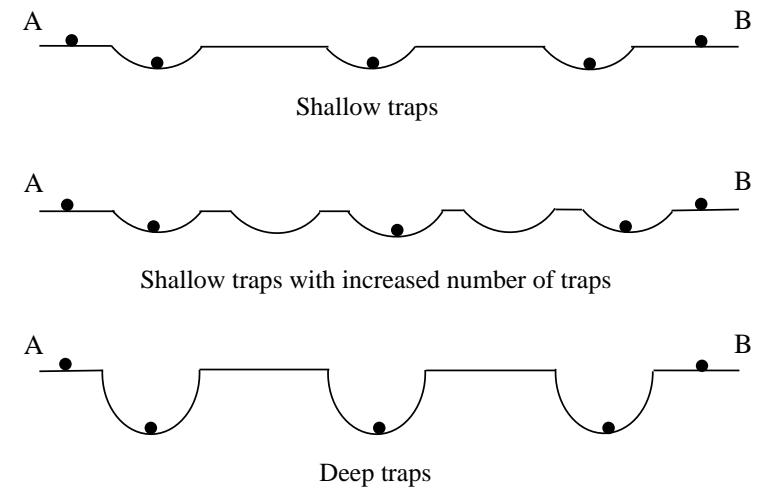

Figure 4. Brief illustration of charges (a black dot) moving from A to B via shallow traps, an increased number of traps, and deep traps.

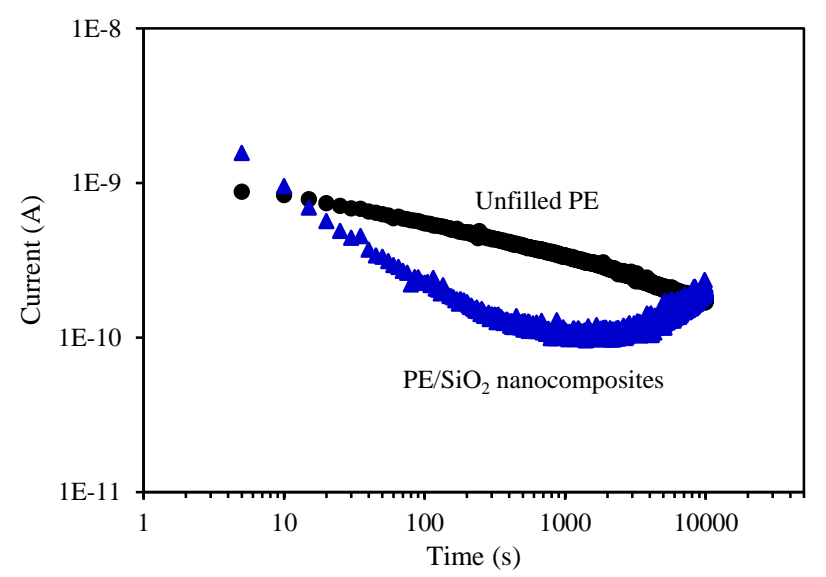

Figure 5. Absorption current behaviors of unfilled $\mathrm{PE}$ and $\mathrm{PE} / \mathrm{SiO}_{2}$ nanocomposites.

phase, corresponding to the initial sharp decrease of current, the rate of decrease of current was significantly greater in all the nanocomposites than in the unfilled PE. This was discussed in terms of increased charge trapping processes (i.e. related to additional interfacial trapping sites). In the second phase, the rate of decrease of current was reduced, which was taken to indicate that the effective mobility of charge carriers was reduced; this was suggested to be a consequence of charge carrier immobilization for a much longer period in localized states (i.e. relatively deep traps). The third phase, characterized by a current rise, was related to the observed reversal of the dominant local space charge from homocharge to heterocharge. Of note, the above observations are not peculiar. The recent work of Virtanen et al [53] indicates that such a time variation in the absorption current behavior of nanocomposites occurs under the influence of water or moisture. Specifically, charge trapping processes at nanocomposite interface can become very different when water is present in the system.

Recently, the influence of water on the behavior of excess electrons at interfaces has been studied theoretically by Saiz and Quirke [43] using ab initio molecular dynamics and densityfunctional theory (see Table 1). In bulk amorphous PE, it was previously shown that an excess electron becomes localized in naturally occurring regions of low density with dimensions of 
Table 1. Representative energy of excess electrons at a number of representative interfaces of polymer nanocomposites [43].

\begin{tabular}{lc}
\hline Material & Energy of Excess Electron \\
\hline Amorphous polyethylene & $-0.20 \mathrm{eV}$ \\
Silica without silanol & $-2.06 \mathrm{eV}$ \\
Silica with less silanol & $-1.65 \mathrm{eV}$ \\
Silica with silanol & $-1.33 \mathrm{eV}$ \\
Silica with more silanol & $-1.25 \mathrm{eV}$ \\
Water & $-0.12 \mathrm{eV}$ \\
Polyethylene/water & $\mathrm{N} / \mathrm{A}$ \\
Polyethylene/silica (without silanol) & $-1.75 \mathrm{eV}$ \\
Polyethylene/silica (with silanol) & $-0.99 \mathrm{eV}$ \\
Silica/water & $-0.27 \mathrm{eV}$ \\
\hline
\end{tabular}

$\sim 0.5 \mathrm{~nm}$ [54]; in the case of a planar amorphous PE slab, the excess electron was, equivalently, found to localize at the $\mathrm{PE} /$ vacuum interface. However, in the case of a PE/water system the electron becomes preferentially located on a water region near the PE interface. All of these results are consistent with the negative electron affinity of $\mathrm{PE}$, whereby this polymer, effectively, "repels injected negative charge carriers". Indeed, based on calculations of the conduction band offset, it was suggested that an excess electron would require $1.69 \mathrm{eV}$ to move from water into PE; i.e. water can be seen to act as a deep trap with respect to this polymer.

In the case of a PE/amorphous silica interface, an excess electron was found to become localized at the $\mathrm{Q}^{4}$ surface with an energy of $-1.75 \mathrm{eV}$; the introduction of increasing numbers of surface silanol groups (i.e. partially hydroxylated, $\mathrm{Q}^{3} / \mathrm{Q}^{4}$ structure) resulted in the electron migrating away from the hydroxyl groups into the silica bulk and becoming less localized, with an energy of $-0.99 \mathrm{eV}$. That is, PE/silica interfaces act as deep traps with energies between $-1.75 \mathrm{eV}$ and $-0.99 \mathrm{eV}$, depending on the degree of hydroxylation; the degree of surface hydroxylation would therefore be expected markedly to influence the behavior of excess electrons near PE/silica interfaces.

Finally, in the case of PE/silica/water, where the influence of PE was considered to be negligible, it was deduced that the excess electron would be preferentially located within the water, with an energy of minus a few tenths of an $\mathrm{eV}$. In summary, this study showed that the presence of water in nanocomposites has a profound impact on the electron trapping behavior, with interfacial water molecules leading to much lower trapping energies and higher excess electron mobility compared to an anhydrous equivalent. This theoretical work therefore aligns well with the experimental work described previously and provides mechanistic understanding of how water molecules can increase electrical conductivity and hence lower the breakdown strength of nanocomposites, independent of the nanofiller surface chemistry itself.

\section{NANOFILLER SURFACE MODIFICATION}

From the above discussion, the potential impact of water on the dielectric properties of nanocomposites is clear. Before we progress further to discuss the exclusion of interfacial water from nanocomposites, we will briefly review two commonly used strategies for the modification of the surface state of nanofillers, namely, chemical functionalization and calcination, since both of these techniques are also closely related to inhibiting water adsorption.

\subsection{CHEMICAL FUNCTIONALIZATION OF NANOFILLERS}

Nanofillers generally have high specific surface area and surface energy [25]. Consequently, they tend to agglomerate when they are added to polymers. Therefore, chemical functionalization of nanofillers is commonly used to modify the interface between the host matrix and the filler, generally, with the aim of improving compatibility between the matrix and the filler and, thereby, reducing the tendency of the nanofiller to agglomerate [11, 25]. However, in addition, chemical functionalization of a nanofiller will often serve to remove surface hydroxyl groups and, consequently, will change the surface from hydrophilic to hydrophobic, leading to suppressed water absorption in nanocomposites [30, 55, 56]. This factor, from the above account, may also directly improve, macroscopic dielectric properties, albeit that the commonly used trimethoxy- or triethoxysilanes are not likely to coordinate fully with nanoparticle surfaces, resulting in some disilyl ether bonding and retained silanol groups.

For example, the previous work of Lau et al [30] on $\mathrm{PE} / \mathrm{SiO}_{2}$ nanocomposites showed that the use of a surface-functionalized $\mathrm{SiO}_{2}$ nanofiller reduced water absorption and, consequently, modified the dielectric response compared to nanocomposites containing an equivalent but unfunctionalized $\mathrm{SiO}_{2}$. The DC breakdown strength of the nanocomposites containing silanefunctionalized $\mathrm{SiO}_{2}$ subsequently improved compared to the systems containing the unfunctionalized $\mathrm{SiO}_{2}[57,58]$. The authors suggested that the addition of functionalized $\mathrm{SiO}_{2}$ to $\mathrm{PE}$ resulted in the creation of a new trap band possessing different characteristics from that of unfunctionalized $\mathrm{SiO}_{2}$, in addition to the localized states that characterized the base polymer. The introduction of additional traps in this way was discussed elsewhere [9] and was considered to be related to the presence of the interface, whereupon, its nature will be influenced by moieties carried on the nanofiller surfaces. The work also anticipated that, by using appropriate chemical functionalization, nanocomposites could have favorable DC breakdown enhancements compared to unfilled polymers.

Praeger et al [38] also reported that hydroxyl groups and water molecules could be eliminated upon chemical functionalization, thus improving the space charge behavior and reducing the conductivity of $\mathrm{PE} / \mathrm{SiO}_{2}$ nanocomposites. These authors suggested that the primary mechanism by which functionalization of the $\mathrm{SiO}_{2}$ surfaces affected macroscopic electrical properties was not through changed interactions between $\mathrm{SiO}_{2}$ and $\mathrm{PE}$ but, rather, through consumption of hydroxyl groups, which directly reduced water absorption and, thereby, indirectly affected charge transport dynamics. Therefore, the removal of hydroxyl groups and water molecules may be an important mechanism by which nanofiller functionalization affects electrical behavior through reduced water uptake and modified charge transport behavior.

According to Yeung et al [55], a significant improvement in breakdown strength of epoxy/SiO${ }_{2}$ nanocomposites could be 
achieved upon optimal $\mathrm{SiO}_{2}$ nanoparticles surface modification. An increase in the breakdown strength of about $47 \%$ was reported for systems formulated with treated $\mathrm{SiO}_{2}$ nanoparticles. Notably, changes in the real permittivity were observed and ascribed to variations in the polar character of the $\mathrm{SiO}_{2}$ nanofiller surface, which may modify the local density of trapping states and, hence, affect charge transport dynamics. By using octyl-trimethoxysilane functionalized $\mathrm{SiO}_{2}$, the dielectric properties of $\mathrm{LLDPE} / \mathrm{SiO}_{2}$ nanocomposites were also demonstrated to improve compared to systems formulated using unfunctionalized $\mathrm{SiO}_{2}$, where functionalized $\mathrm{SiO}_{2}$ changed the morphology, breakdown field, charging current, water treeing behavior and the frequency dependence of dielectric parameters of $\mathrm{LLDPE} / \mathrm{SiO}_{2}$ nanocomposites [29].

Although nanofiller surface functionalization promises improved dielectric properties, the dielectric effects brought about by nanofiller surface functionalization can be complex. For example, Roy et al [33] reported that no significant difference or improvement in the breakdown strength of $\mathrm{XLPE} / \mathrm{SiO}_{2}$ nanocomposites was caused by surface functionalization of $\mathrm{SiO}_{2}$ and ascribed this to the imperfection of the chemical reaction between XLPE and $\mathrm{SiO}_{2}$. Similarly, Praeger et al [38] highlighted that the property differences between $\mathrm{PE} / \mathrm{SiO}_{2}$ nanocomposites formulated with differently functionalized $\mathrm{SiO}_{2}$ were in general small compared to experimental errors; the differences, if any, were mainly attributed to variations in water content. In addition, the presence of chemical residues may complicate matters. In fact, in the series of chemically functionalized nanofillers used in the work of Lau et al [59], the presence of chemical residues or impurities was found to lead to lowered breakdown strength. Indeed, according to Sung et al [60], the presence of chemical residues after nanofiller functionalization is effectively inevitable.

\subsection{CALCINATION OF NANOFILLERS}

Recently, calcination of nanofillers has been proposed as an effective strategy to reduce adsorbed water on the surface of nanofillers, in the absence of complicating issues involving chemical modification/chemical residues. Calcination is a hightemperature treatment process [61], which can result in physical and chemical changes. Specifically, calcination can be effective in reducing the tendency of nanofillers to interact with water [46]. According to the literature [44, 45], calcination temperatures around $1000{ }^{\circ} \mathrm{C}$ can eliminate moisture or surface hydroxyl groups surrounding $\mathrm{SiO}_{2}$. Peng et al [46] demonstrated that physically adsorbed water could be effectively removed when their $\mathrm{SiO}_{2}$ nanofiller was calcined between $600{ }^{\circ} \mathrm{C}$ and $800{ }^{\circ} \mathrm{C}$. Also, $\mathrm{SiO}_{2}$ tended to absorb much less water after calcination. Similarly, Mayabadi et al [62] found that applying a calcination process to nanofillers had a significant impact and led to promising potential for the application of stannic oxide $\left(\mathrm{SnO}_{2}\right)$ /titanium dioxide $\left(\mathrm{TiO}_{2}\right)$ nanocomposites in optical and photoelectrochemical research.

Praeger et al [63] considered nanofiller calcination from the perspective of dielectrics and showed that the breakdown strength of $\mathrm{PE} / \mathrm{SiO}_{2}$ nanocomposites was enhanced after calcining $\mathrm{SiO}_{2}$ at $1050{ }^{\circ} \mathrm{C}$. This was attributed to the successful removal of polar moieties on the $\mathrm{SiO}_{2}$. Further research by the same group [31, 64] indicated that calcining nanofillers at $1050{ }^{\circ} \mathrm{C}$ was indeed effective in modifying the surface chemistry of nanofillers, inhibiting water uptake and enhancing breakdown strength. For example, nanocomposites containing calcined $\mathrm{SiO}_{2}$ evinced much reduced water uptake compared to equivalent systems containing uncalcined $\mathrm{SiO}_{2}$, when subjected to ambient conditioning. The DC breakdown strength of nanocomposites containing calcined $\mathrm{SiO}_{2}$ subsequently improved by about $86 \%$ compared to uncalcined $\mathrm{SiO}_{2}$ at a $5 \mathrm{wt} \% \mathrm{SiO}_{2}$ loading level.

Meanwhile, Peng et al [46] suggested that physically adsorbed water could be completely removed when $\mathrm{SiO}_{2}$ was heated between $600{ }^{\circ} \mathrm{C}$ and $800{ }^{\circ} \mathrm{C}$. At a low temperature of $50{ }^{\circ} \mathrm{C}$, physically adsorbed water could not be eliminated on the surface of the nanofiller. However, by increasing the temperature to $800^{\circ} \mathrm{C}$ and heating for $3 \mathrm{~h}$, physically adsorbed water was expected to be completely removed. According to Zhuravlev et al [44, 45], different phases of water can be removed from $\mathrm{SiO}_{2}$ at different nanofiller calcination temperatures. First, calcination temperatures of $25-190{ }^{\circ} \mathrm{C}$ resulted in the removal of physically adsorbed water. Second, calcination temperatures in the range $190-400{ }^{\circ} \mathrm{C}$ were effective for the removal of surface silanol groups, leaving the nanofiller's surface comparable to the $\mathrm{Q}^{3} / \mathrm{Q}^{4}$ surfaces considered in the work of Saiz and Quirke [43]; in the context of calcination efficacy, these may be termed partially dehydroxylated. Lastly, calcination temperatures of around 400-900 ${ }^{\circ} \mathrm{C}$ resulted in the removal of internal silanol groups. The dehydroxylation process (the removal of silanol groups) continued to increase for calcination temperature higher than $900{ }^{\circ} \mathrm{C}$, which will eventually lead to the ideal, fully dehydroxylated $\mathrm{Q}^{4}$ surface structure also considered by Saiz and Quirke [43]. Consequently, nanofillers treated at very high temperatures become much less susceptible to rehydroxylation.

Calcination is, however, not solely related to removal of water and hydroxyl groups from the system. High calcination temperatures can also affect the structure and agglomeration state of the nanofiller, in addition to the surface chemistry. For example, Halim et al [65] found that the use of high calcination temperatures resulted in the agglomeration of catalyst particles, thus decreasing their surface area. This occurred on modestly increasing the calcination temperature from $900{ }^{\circ} \mathrm{C}$ to just $1100{ }^{\circ} \mathrm{C}$. Furthermore, calcination can also cause structural reorganization in the bulk, e.g. relieving strained siloxane bridges. Indeed, Opalinska et al [66] reported on the influence of calcination temperature up to $1100{ }^{\circ} \mathrm{C}$ on nanozirconia $\left(\mathrm{ZrO}_{2}\right)$ and suggested that calcining this nanofiller resulted in physical changes to the nanofiller in addition to the elimination of surface groups. Specifically, an increase in the density of $\mathrm{ZrO}_{2}$ was observed, mainly, due to a reduction in the overall fraction of surface regions which were characterized by a lower density than the bulk; this occurred together with the removal of water molecules and sub-surface hydroxyl groups from their $\mathrm{ZrO}_{2}$ nanofiller.

To summarize, nanofiller calcination has been demonstrated to be effective in modifying nanofiller surface regions and hence will affect interfaces within nanocomposites in ways that potentially improve the dielectric properties of nanocomposites 
through mechanisms such as those revealed by the simulation studies discussed above. Such effect will depend on calcination parameters and upon the type of nanofiller. Nevertheless, how changes in calcination temperature affect the structure and surface chemistry of nanofillers, water accumulation processes and hence the dielectric properties of nanocomposites have attracted little attention.

\section{RECENT INSIGHTS FROM NANOFILLER CALCINATION}

In view of the profound impact of water on the dielectric properties of nanocomposites and the effectiveness of calcination in removing polar moieties associated with water adsorption onto nanofillers, we have recently explored further how different nanofiller calcination temperatures could affect the water uptake and structure of two nanofillers, i.e., $\mathrm{SiO}_{2}$ and $\mathrm{ZrO}_{2}$. The rationale behind the choice of $\mathrm{SiO}_{2}$ and $\mathrm{ZrO}_{2}$ was that both nanofillers are oxides, with an average particle size of $20 \mathrm{~nm}$. This allowed a comparable evaluation of the effectiveness of nanofiller calcination in removing waterrelated components and effecting structural changes in such nanofillers and, hence, influencing the behavior of oxide-based nanocomposites. Dielectric property variations relevant to these changes can therefore be comparatively assessed.

\subsection{CALCINATION AND NANOFILLER STRUCTURE}

Figure 6 shows mass change data obtained from $\mathrm{SiO}_{2}$ and $\mathrm{ZrO}_{2}$ nanopowders by thermogravimetric analysis (TGA). For the $\mathrm{SiO}_{2}$ nanopowder, a total mass reduction of about $8 \%$ occurred in three phases, within the temperature range considered here. First, a noticeable reduction in mass $(\sim 5 \%)$ is evident on heating up to $100{ }^{\circ} \mathrm{C}$. Second, a progressive mass reduction $(\sim 3 \%)$ occurred from $100^{\circ} \mathrm{C}$ to $600^{\circ} \mathrm{C}$. Finally, minor mass changes were noticed up to $900{ }^{\circ} \mathrm{C}$. These results indicate that surface hydroxyl groups could be successfully removed from the $\mathrm{SiO}_{2}$ nanopowder, but that the extent of the removal depends on the temperature. Zhuravlev et al's model for the calcination of $\mathrm{SiO}_{2}$ considers that the elimination of physically adsorbed water, surface hydroxyl groups, and internal hydroxyl groups within $\mathrm{SiO}_{2}$ can be attained at $25-190{ }^{\circ} \mathrm{C}, 190-400{ }^{\circ} \mathrm{C}$, and $400-900{ }^{\circ} \mathrm{C}$, respectively [44, 45].

For the $\mathrm{ZrO}_{2}$ nanopowder, a total mass reduction of only $\sim 1.5 \%$ occurred within the complete temperature range, which seemed to occur in two phases. Initially, a reduction in mass of $\sim 1 \%$ occurred on heating up to $100{ }^{\circ} \mathrm{C}$. Subsequently, only a marginal change in mass of $\sim 0.5 \%$ occurred between 100 and $900{ }^{\circ} \mathrm{C}$. This suggests that the primary source of mass loss in $\mathrm{ZrO}_{2}$ corresponds to the removal of physically adsorbed water and that changes in water content in $\mathrm{ZrO}_{2}$ are less significant than in $\mathrm{SiO}_{2}$. Although both $\mathrm{SiO}_{2}$ and $\mathrm{ZrO}_{2}$ are oxide-based nanofillers, these TGA data imply that $\mathrm{ZrO}_{2}$ generally contains fewer polar species than $\mathrm{SiO}_{2}$, such that water-related effects seen in $\mathrm{SiO}_{2}$-based nanocomposites should be less pronounced in nanocomposites based upon $\mathrm{ZrO}_{2}$.

Figure 7 compares SEM micrographs of the uncalcined $\mathrm{SiO}_{2}$ and $\mathrm{ZrO}_{2}$ nanopowders with equivalent images of $\mathrm{SiO}_{2}$ and $\mathrm{ZrO}_{2}$ nanopowders calcined at $900{ }^{\circ} \mathrm{C}$. For the uncalcined $\mathrm{SiO}_{2}$ nanopowder, the appearance is not of separate nanometer-sized

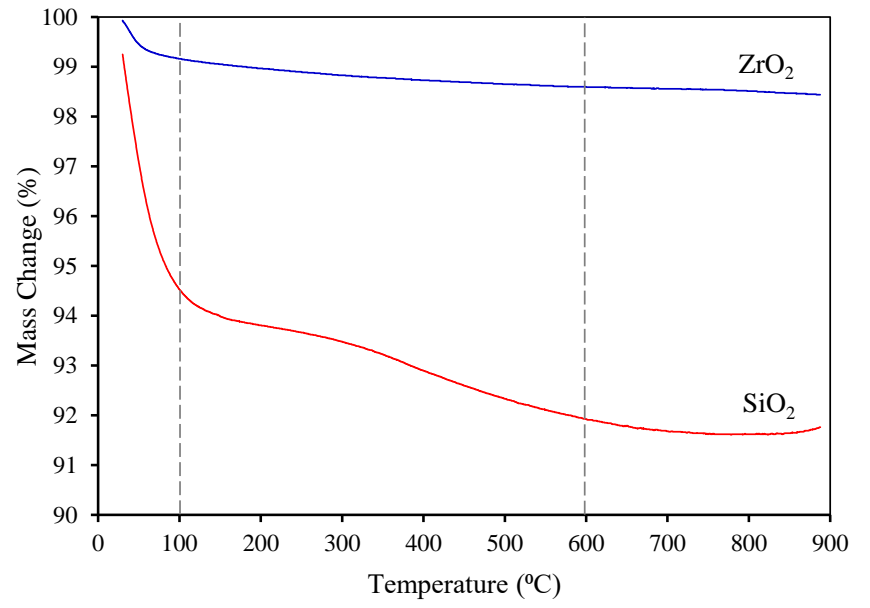

Figure 6. TGA curve for $\mathrm{SiO}_{2}$ and $\mathrm{ZrO}_{2}$ nanopowder.
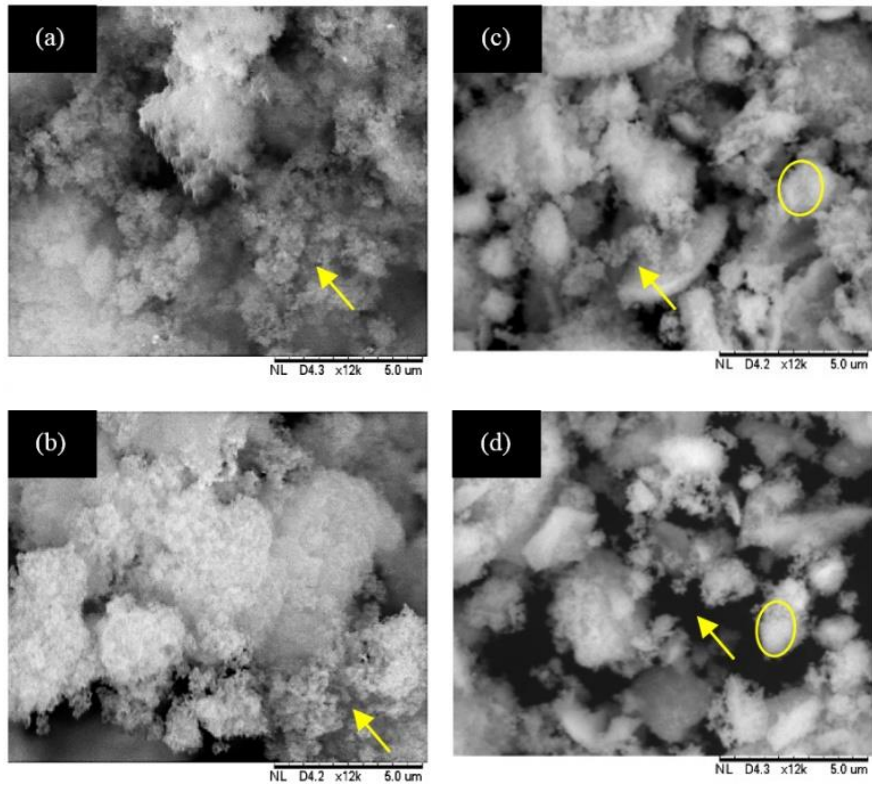

Figure 7. $\mathrm{SEM}$ micrographs of (a) uncalcined $\mathrm{SiO}_{2}$ nanopowder (b) $\mathrm{SiO}_{2}$ nanopowder calcined at $900{ }^{\circ} \mathrm{C}$ (c) uncalcined $\mathrm{ZrO}_{2}$ nanopowder (d) $\mathrm{ZrO}_{2}$ nanopowder calcined at $900{ }^{\circ} \mathrm{C}$. The arrow indicates loosely bound agglomeration while the circle indicates closely bound aggregation.

particles but, rather, of agglomerated entities that appear somewhat "fluffy" (arrowed in Figure 7a). It has been reported that nanoparticles commonly present as agglomerates rather than isolated particles [66]. Nanometer-sized distributions of $\mathrm{SiO}_{2}$ nanopowder remained difficult to identify even after $\mathrm{SiO}_{2}$ calcination (see Figure 7b), suggesting that the calcination process does not fundamentally affect the morphology of the system. Nevertheless, the SEM morphology of nanocomposite samples containing calcined $\mathrm{SiO}_{2}$ revealed a more significant number of fine particles compared to nanocomposite samples containing an equivalent uncalcined $\mathrm{SiO}_{2}$ counterparts [67]. This leads to two possibilities. First, that different calcination temperatures alter the phase structure, size distribution or pore structures of the investigated nanoparticles, as suggested by Tian et al [68]. Second, that different calcination temperatures beneficially alter the surface chemistry of the $\mathrm{SiO}_{2}$, thus reducing the propensity of the nanoparticles to agglomerate within the non-polar PE matrix [69]. Since high-temperature 
annealing would be expected to promote particle coalescence and in the light of the thoroughly invested consequences of $\mathrm{SiO}_{2}$ calcination $[44,45]$, the latter is thought to be more relevant for these $\mathrm{SiO}_{2}$-based nanocomposites.

From the SEM morphology of the uncalcined $\mathrm{ZrO}_{2}$ nanopowder, the $\mathrm{ZrO}_{2}$ was, again, agglomerated into entities that looked somewhat "fluffy" or loosely bound in nature (arrowed in Figure 7c). Additionally, a proportion of the nanopowder appeared to exist in the form of more closely bound aggregations, as evinced by the object circled in Figure 7c. Of note, we use the terms "agglomeration" and "aggregation" to represent two different structures: agglomeration is a loose assembly of smaller entities; aggregation develops when primary particles start to coalesce to form a typical crystalline structure [70]. Nevertheless, the prevalence of loosely bound agglomerations of $\mathrm{ZrO}_{2}$ nanopowder reduced after calcination, as shown in Figure $7 \mathrm{~d}$. This implies structural reorganization of the $\mathrm{ZrO}_{2}$ upon calcination, reducing the overall surface energy of the system. We therefore infer that calcination of $\mathrm{ZrO}_{2}$ affects the particle size and structure of $\mathrm{ZrO}_{2}$, in addition to removal of the minimal water shown in Figure 6. This is supported by previous studies $[68,69,71]$, where the phase structure, particle size, and pore structure of several different nanoparticle systems were shown to be affected by calcination.

The above suggest that, for $\mathrm{SiO}_{2}$, different calcination temperatures mainly alter the surface chemistry, such that $\mathrm{SiO}_{2}$ becomes less hydrophilic. Calcining $\mathrm{ZrO}_{2}$ primarily changes the size and structure of the $\mathrm{ZrO}_{2}$ and that these changes are more significant than water-related surface changes.

\subsection{DIELECTRIC CHANGES OF NANOCOMPOSITES AFTER NANOFILLER CALCINATION}

The above discussion highlights that calcination affects $\mathrm{SiO}_{2}$ and $\mathrm{ZrO}_{2}$ in distinctly different ways, which should be reflected in the dielectric properties of resulting nanocomposites. In considering this, we will first focus on the effect of waterrelated moieties on FTIR spectra obtained from nanocomposites containing uncalcined and calcined $\mathrm{SiO}_{2}$ and $\mathrm{ZrO}_{2}$, referenced to unfilled PE (see Figure 8). While a detailed interpretation of the complete FTIR spectra can be obtained elsewhere [67, 72], in short, the inclusion of $8 \mathrm{wt} \%$ of uncalcined $\mathrm{SiO}_{2}$ within PE (S/8/0) results in increased FTIR absorbance around $3400 \mathrm{~cm}^{-1}$ and $1600 \mathrm{~cm}^{-1}$ (arrowed in Figure 8 ) due to the presence of hydroxyl groups and water molecules around the $\mathrm{SiO}_{2}$. Nevertheless, with the addition of $8 \mathrm{wt} \%$ of $\mathrm{SiO}_{2}$ calcined at $600{ }^{\circ} \mathrm{C}(\mathrm{S} / 8 / 600)$, the IR absorbance around $3400 \mathrm{~cm}^{-1}$ and $1600 \mathrm{~cm}^{-1}$ is reduced and further reduced with the addition of $8 \mathrm{wt} \%$ of $\mathrm{SiO}_{2}$ calcined at $900{ }^{\circ} \mathrm{C}(\mathrm{S} / 8 / 900)$. This suggests that calcination of $\mathrm{SiO}_{2}$ reduces the number of hydroxyl groups present and the amount of water that is absorbed by the resulting $\mathrm{SiO}_{2}$-based nanocomposites and that calcining $\mathrm{SiO}_{2}$ at higher temperatures increases the efficacy of the process. This influences the nanoparticle/polymer interfacial regions, the local interactions between $\mathrm{PE}$ and $\mathrm{SiO}_{2}$ and also related trapping states. Conversely, in $\mathrm{ZrO}_{2}$-based systems, nanofiller calcination results in insignificant variations in the strength of the absorbance at $3400 \mathrm{~cm}^{-1}$ and $1600 \mathrm{~cm}^{-1}$. Evidently, the effect on the $\mathrm{ZrO}_{2}$ nanofiller of the imposed

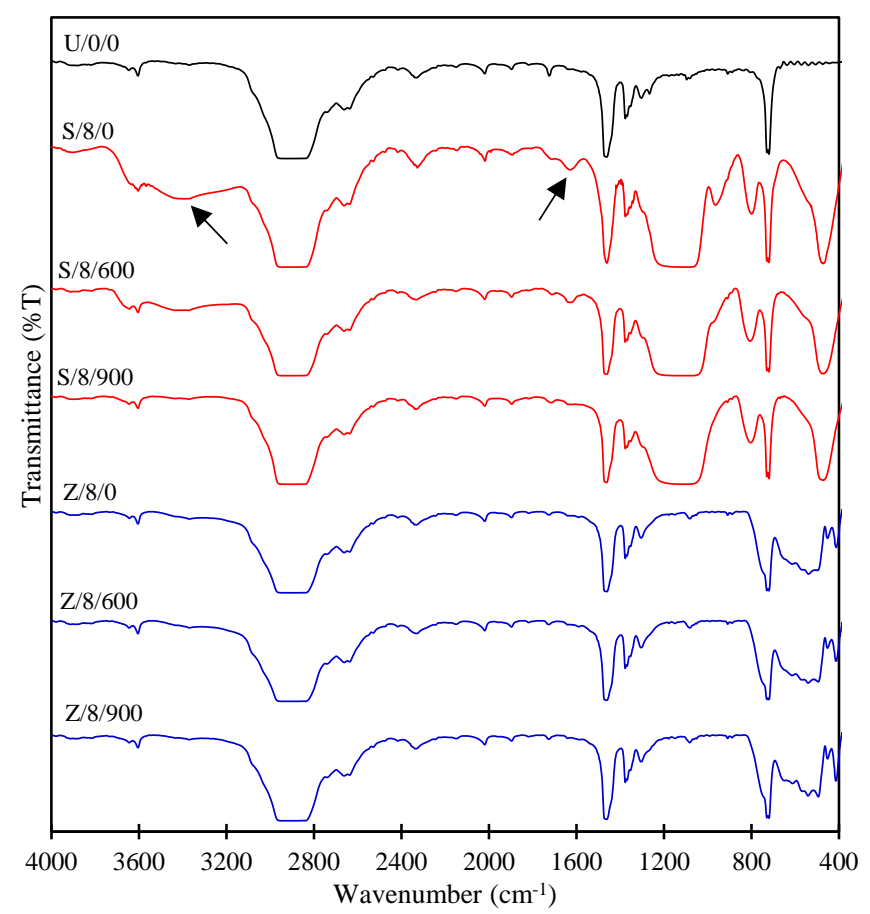

Figure 8. FTIR spectra comparing unfilled $\mathrm{PE}$ and nanocomposites containing uncalcined and calcined $\mathrm{SiO}_{2}$ and $\mathrm{ZrO}_{2}$.

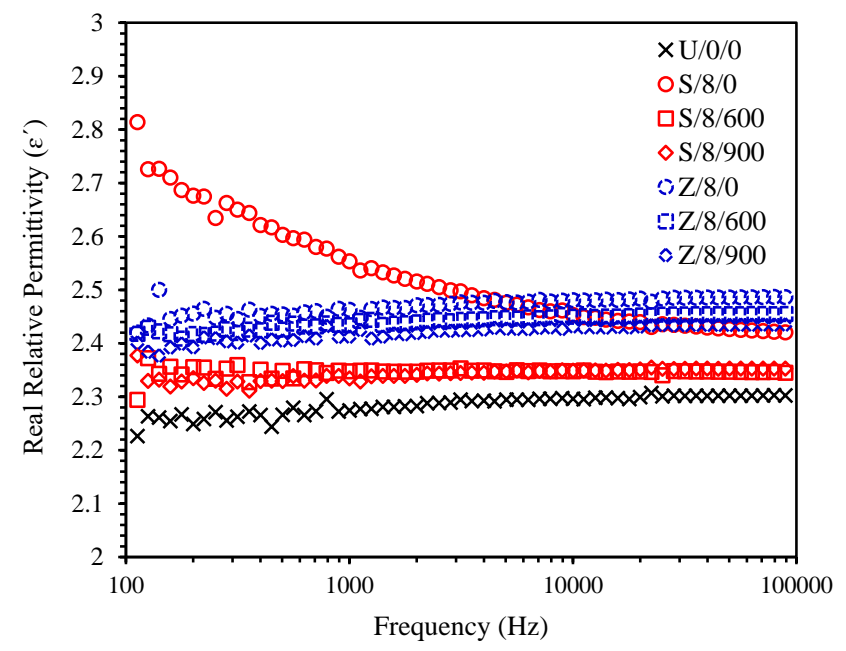

Figure 9. Real permittivity of unfilled $\mathrm{PE}$ and nanocomposites containing uncalcined and calcined $\mathrm{SiO}_{2}$ and $\mathrm{ZrO}_{2}$.

thermal treatments was insufficient to be detected by FTIR. The FTIR spectra of all three $\mathrm{ZrO}_{2}$-based nanocomposites exhibit comparable levels of absorbance at $3400 \mathrm{~cm}^{-1}$ and $1600 \mathrm{~cm}^{-1}$ to the unfilled PE reference, implying that the presence of water in $\mathrm{ZrO}_{2}$-based nanocomposites was minimal. This marked difference in behavior between $\mathrm{SiO}_{2}$ - and $\mathrm{ZrO}_{2}$-based systems is consistent with the TGA results presented previously.

Such observations are pertinent to changes in the dielectric response of the nanocomposites, as shown in Figure 9. The increase in permittivity of nanocomposites containing $8 \mathrm{wt} \%$ of uncalcined $\mathrm{SiO}_{2}(\mathrm{~S} / 8 / 0)$ is mainly a result of interfacial relaxation processes related to the presence of hydroxyl groups and water molecules at the interface of $\mathrm{SiO}_{2}$-based nanocomposites, as discussed elsewhere [30]. This effect was particularly pronounced with increasing amounts of $\mathrm{SiO}_{2}$ (in 


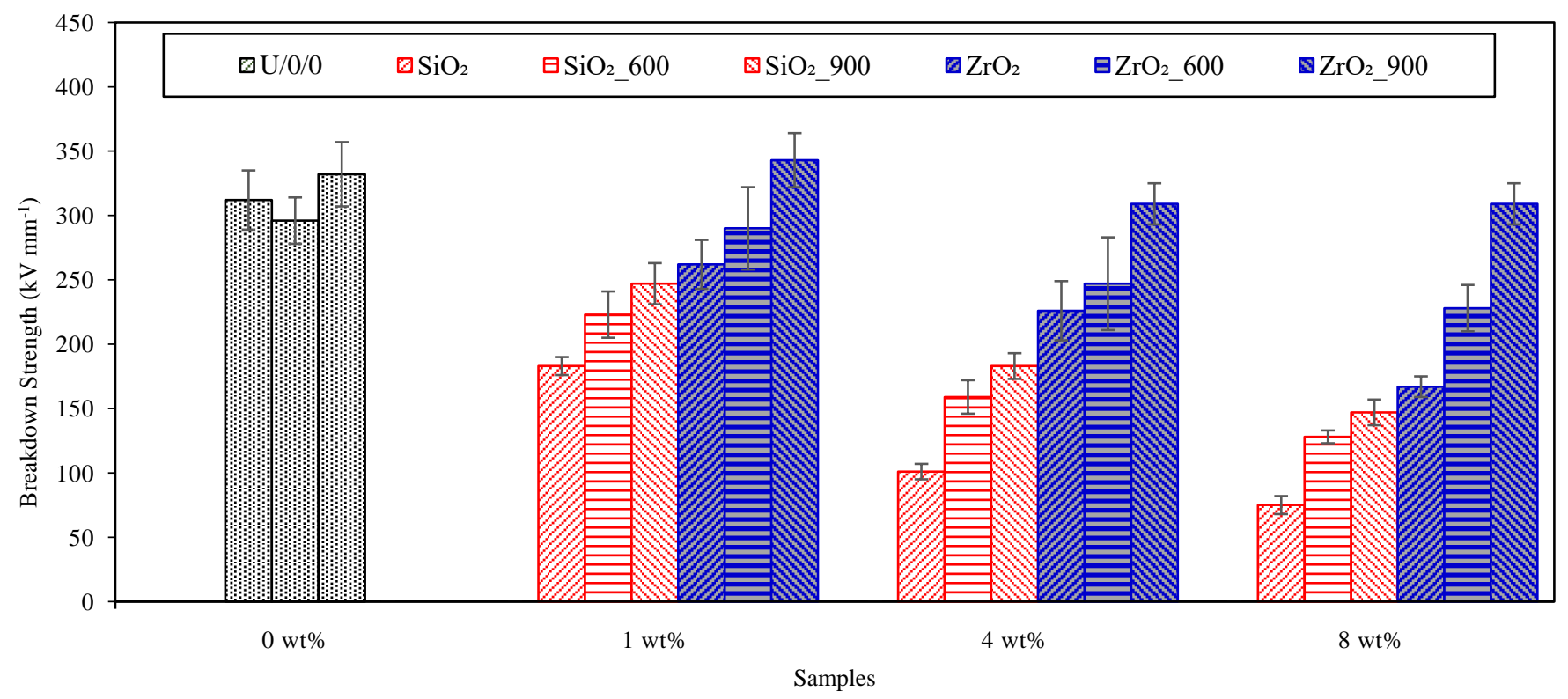

Figure 10. Comparison of DC breakdown strength for unfilled $\mathrm{PE}$ and nanocomposites containing uncalcined and calcined $\mathrm{SiO}_{2}$ and $\mathrm{ZrO}_{2}$.

this case, $8 \mathrm{wt} \%$ ), where more water molecules and surface hydroxyl groups would be present within the system as a consequence of the increase in the total interfacial area. This, potentially, influences the dielectric response in two ways: the number of dipolar species, impurities, ions, etc. would be increased, facilitating an increase of the interfacial polarization [73]; nanoparticle separation is reduced, so increasing the probability of the onset of percolation effects [35].

The permittivity of nanocomposites containing $8 \mathrm{wt} \%$ of $\mathrm{SiO}_{2}$ calcined at $600{ }^{\circ} \mathrm{C}(\mathrm{S} / 8 / 600)$ was reduced compared to nanocomposites containing $8 \mathrm{wt} \%$ of uncalcined $\mathrm{SiO}_{2}(\mathrm{~S} / 8 / 0)$. For nanocomposites containing $\mathrm{SiO}_{2}$ calcined at $900{ }^{\circ} \mathrm{C}$ (S/8/900), a further reduction in real permittivity could be observed. Therefore, by judiciously selecting the calcination conditions, the permittivity of $\mathrm{SiO}_{2}$-based nanocomposites was significantly reduced. This is ascribed to reduced numbers of water molecules and hydroxyl groups at the interface [74].

Since uncalcined $\mathrm{ZrO}_{2}$ only contained physically adsorbed water and some hydroxyl groups, the permittivity of nanocomposites containing uncalcined $\mathrm{ZrO}_{2}(\mathrm{Z} / 8 / 0)$ was higher than the unfilled PE (U/0/0), but lower than nanocomposites containing uncalcined $\mathrm{SiO}_{2}(\mathrm{~S} / 8 / 0)$. The slightly decreased permittivity values found in nanocomposites containing calcined $\mathrm{ZrO}_{2}(\mathrm{Z} / 8 / 600)$ is, therefore, a direct consequence of the effectiveness of this calcination process in removing the majority of water-related species [56]. This agrees well with the above TGA data and relevant literature [30,35], where the additional contributor for the increase in permittivity was physically adsorbed water. In addition, changes in the structure of $\mathrm{ZrO}_{2}$ may result in improved interactions between calcined $\mathrm{ZrO}_{2}$ and PE. This will serve to lower the permittivity of the nanocomposites comprising calcined $\mathrm{ZrO}_{2}$ compared to equivalent amounts of uncalcined $\mathrm{ZrO}_{2}$ [75].

Figure 10 compares the DC breakdown strength of nanocomposites containing uncalcined $\mathrm{SiO}_{2}$ and $\mathrm{ZrO}_{2}$ with nanocomposites containing $\mathrm{SiO}_{2}$ and $\mathrm{ZrO}_{2}$ calcined at $600{ }^{\circ} \mathrm{C}$ and $900{ }^{\circ} \mathrm{C}$ (at $1 \mathrm{wt} \%, 4 \mathrm{wt} \%$, and $8 \mathrm{wt} \%$ loading levels); the unfilled PE serves as a reference. With uncalcined $\mathrm{SiO}_{2}$, the DC breakdown strength reduced significantly compared to the unfilled PE; the reduction becoming more pronounced as the loading level increased. While the reduction in the DC breakdown strength may be influenced by agglomeration effects [76, 77], the results from FTIR and dielectric spectroscopy suggest that the presence of hydroxyl groups and water molecules within nanocomposites is likely also to be important, since water can have considerable adverse effects under DC fields [26, 27, 34]. As discussed earlier based on the work of Saiz and Quirke [43], a wet interface within nanocomposites produces much lower trapping energies and results in an increase in the excess electron mobility compared to the dry material, which can lead to lowered breakdown strength. Higher DC breakdown strength was observed with the addition of $\mathrm{SiO}_{2}$ calcined at $600{ }^{\circ} \mathrm{C}$ to $\mathrm{PE}$. By increasing the $\mathrm{SiO}_{2}$ calcination temperature to $900^{\circ} \mathrm{C}$, a further enhancement in DC breakdown strength was obtained. This can be further explained from the FTIR and dielectric spectroscopy data; successful dehydroxylation driven by calcination enhances the DC breakdown performance of the materials. These DC breakdown enhancements are therefore mainly related to changes in the interfacial chemistry of the $\mathrm{SiO}_{2}$-based nanocomposites as a consequence of the reduced hydroxyl content after calcination and the consequent reduced propensity for accumulation of water at such sites through hydrogen bonding. Nevertheless, none of the materials exhibited a higher DC breakdown strength than the unfilled PE and, even after treatment at $900{ }^{\circ} \mathrm{C}$ which, from TGA corroborated by FTIR and dielectric data, would be expected to remove the vast majority of water, surface silanol and bulk silanol groups. This demonstrates that removal of such polar groups is no panacea as far as breakdown strength is concerned.

Comparing the dependence of breakdown strength on nanofiller calcination seen with $\mathrm{SiO}_{2}$ with the influence of the same thermal treatment on $\mathrm{ZrO}_{2}$ reveals telling differences. First, uncalcined $\mathrm{ZrO}_{2}$ contains relatively few hydroxyl groups 
and water - as evinced by both TGA and FTIR data. If the mechanism by which calcination influences breakdown strength in nanocomposites were solely through removal of such polar moieties, then calcination should be ineffective at improving the behavior of $\mathrm{ZrO}_{2}$-based systems. Clearly, from Figure 10, this is not the case. Indeed, Figure 10 shows a pronounced increase in breakdown strength on increasing the calcination temperature from $600{ }^{\circ} \mathrm{C}$ to $900{ }^{\circ} \mathrm{C}$ - a temperature change that has no effect on the water/hydroxyl content of system (see Figures 6 and 8). Rather, we suggest that this may be related to $\mathrm{ZrO}_{2}$ structural factors. For example, the simulations of Saiz and Quirke [43] demonstrated charge trapping within nanoparticles; presumably, thermally-induced internal structural rearrangements will influence such processes. In addition, changes in the surface structure that reduce the specific surface energy may influence propensity for agglomeration. Finally, it is well appreciated that, in semicrystalline polymers, where secondary nucleation dominates, that structural features on surfaces can markedly affect the process of polymer crystallization (grapho-epitaxy). While such structural factors were overshadowed by water-related phenomena in $\mathrm{SiO}_{2}$-based nanocomposites, in $\mathrm{ZrO}_{2}$, their influence becomes more influential, affecting the trapping behavior, the mobility of excess electrons, the material's electrical conductivity and, thereby, its breakdown strength [43]. Although the inclusion of calcined $\mathrm{ZrO}_{2}$ in the apparent absence of water does not result in significantly improved nanocomposite breakdown strength over unfilled PE, the comparable performance of nanocomposites containing $1 \mathrm{wt} \%$ of $\mathrm{ZrO}_{2}$ calcined at $900{ }^{\circ} \mathrm{C}$ and unfilled PE does suggest that in seeking to engineer the dielectric properties of nanocomposites, consideration of removal of water adsorbed onto nanofillers is important.

\section{CLOSING REMARKS}

In high voltage insulation, polymer nanocomposites have attracted significant interest for many years, due to the dielectric property enhancements that have been reported in many studies. For these materials, the addition of nanoparticles to polymers is expected to influence the interactions between the base polymers and the nanofillers, thus resulting in unique macroscopic properties. However, the presence of hydroxyl groups, especially on the surface of oxide-based nanofillers, often results in detrimental effects, due to the affinity of water to associate with these groups. The preceding account reviews the importance of removing interfacial water within nanocomposites and contrast our experimental results obtained from calcination of $\mathrm{SiO}_{2}$ and $\mathrm{ZrO}_{2}$ nanofillers, with $\mathrm{SiO}_{2}$ more prone to water absorption than $\mathrm{ZrO}_{2}$. The addition of these calcined nanofillers to PE improves dielectric performance of the nanocomposites. Specifically, changes in water-related surface chemistry after nanofiller calcination are favorable for nanocomposites as far as DC breakdown performance is concerned. Furthermore, nanofiller calcination affects not only the water-related chemistry, but also the structure of oxidebased nanofillers. Of note, the current review does not attempt to explain all phenomena exhibited by nanocomposites by referring to the examples addressed. Nevertheless, it signifies that, for the detailed interfacial chemistry of nanofillers to become relevant in engineering the dielectric properties of nanocomposites, the effective removal of interfacial water adsorbed onto nanofillers is critical.

\section{ACKNOWLEDGMENTS}

The authors acknowledge Malaysia Ministry of Education, Universiti Teknologi Malaysia, and Nippon Sheet Glass Foundation for Materials Science and Engineering for financial sponsorship and the respective FRGS (FRGS/1/2019/TK04/UTM/02/1), RUG (16J55), and NSG (4B373) research grants.

\section{REFERENCES}

[1] M. Naidu and V. Kamaraju, High Voltage Engineering, India: McGrawHill, 2009.

[2] S. Z. A. Dabbak et al "Electrical properties of polyethylene/polypropylene compounds for high-voltage insulation," Energies, vol. 11, no. 6, pp. 1-13, 2018.

[3] K. Barber and G. Alexander, "Insulation of electrical cables over the past 50 years," IEEE Electr. Insul. Mag., vol. 29, no. 3, pp. 27-32, 2013.

[4] T. Tanaka and T. Imai, "Advances in nanodielectric materials over the past 50 years,” IEEE Electr. Insul. Mag., vol. 29, no. 1, pp. 10-23, 2013.

[5] K. Y. Lau, A. S. Vaughan, and G. Chen, "Nanodielectrics: opportunities and challenges," IEEE Electr. Insul. Mag., vol. 31, vol. 4, pp. 45-54, 2015.

[6] T. J. Lewis, "Nanometric dielectrics," IEEE Trans. Dielectr. Electr. Insul., vol. 1, no. 5, pp. 812-825, 1994.

[7] G. C. Psarras, "Nanodielectrics: an emerging sector of polymer nanocomposites," Express Polym. Lett., vol. 2, no. 7, pp. 460, 2008.

[8] M. F. Frechette et al, "Introductory remarks on nanodielectrics," IEEE Trans. Dielectr. Electr. Insul., vol. 11, no. 5, pp. 808-818, 2004.

[9] T. Tanaka, "Dielectric nanocomposites with insulating properties," IEEE Trans. Dielectr. Electr. Insul., vol. 12, no. 5, pp. 914-928, 2005.

[10] T. J. Lewis, "Interfaces are the dominant feature of dielectrics at the nanometric level," IEEE Trans. Dielectr. Electr. Insul., vol. 11, no. 5, pp. 739-753, 2004.

[11] T. Tanaka et al, "Proposal of a multi-core model for polymer nanocomposite dielectrics," IEEE Trans. Dielectr. Electr. Insul. vol. 12, no. 4, pp. 669-681, 2005.

[12] S. Li et al, "Short-term breakdown and long-term failure in nanodielectrics: a review," IEEE Trans. Dielectr. Electr. Insul., vol. 17, no. 5, pp. 1523-1535, 2010.

[13] S. Singha and M. Thomas, "Dielectric properties of epoxy nanocomposites," IEEE Trans. Dielectr. Electr. Insul., vol. 15, no. 1, pp. 12-23, 2008.

[14] S. Raetzke and J. Kindersberger, "Role of interphase on the resistance to high-voltage arcing, on tracking and erosion of silicone/ $\mathrm{SiO}_{2}$ nanocomposites," IEEE Trans. Dielectr. Electr. Insul. vol. 17, no. 2, pp. 607-614, 2010.

[15] C. Daily et al "Modeling the interphase of a polymer-based nanodielectric,” IEEE Trans. Dielectr. Electr. Insul. vol. 21, no. 2, pp. 488-496, 2014.

[16] T. Tanaka, "A Quantum Dot Model for Nanoparticles in Polymer Nanocomposites," IEEE Trans. Dielectr. Electr. Insul. vol. 26, no. 1, pp. 276-283, 2019.

[17] F. N. Alhabill et al, "Introducing particle interphase model for describing the electrical behaviour of nanodielectrics," Mater. Des. vol. 158, pp. 62$73,2018$.

[18] J. K. Nelson and L. S. Schadler, "Nanodielectrics - III.," IEEE Trans. Dielectr. Electr. Insul., vol. 21, no. 2, pp. 411, 2014.

[19] T. Tanaka, "Polymer nanocomposites as dielectrics and electrical insulation - perspectives for processing technologies, material characterization and future applications," IEEE Trans. Dielectr. Electr. Insul., vol. 11, no. 5, pp. 763-784, 2004. 
[20] Y. Cao and P. C. Irwin, "The future of nanodielectrics in the electrical power industry,” IEEE Trans. Dielectr. Electr. Insul., vol. 11, no. 5, pp. 797-807, 2004.

[21] C. Mayoux, "Degradation of insulating materials under electrical stress," IEEE Trans. Dielectr. Electr. Insul., vol. 7, no. 5, pp. 590-601, 2000.

[22] W. Wang et al, "Characteristics on breakdown performance of polyethylene/silica dioxide nanocomposites," Ann. Rep. Conf. Electr. Insul. Dielectr. Phenom. (CEIDP), 2012, pp. 521-524.

[23] I. A. Tsekmes et al, "Enhancing the thermal and electrical performance of epoxy microcomposites with the addition of nanofillers. IEEE Electr. Insul. Mag., vol. 31, no. 3, pp. 32-42, 2015.

[24] M. F. Frechette et al, "Nanodielectrics - a panacea for solving all electrical insulation problems?" IEEE Int. Conf. Solid Dielectr. (ICSD), 2010, pp. 1-29.

[25] M. Khalil, "The Role of $\mathrm{BaTiO}_{3}$ in modifying the DC breakdown strength of LDPE,” IEEE Trans. Dielectr. Electr. Insul., vol. 7, no. 2, pp. 261-268, 2000.

[26] X. Huang, Z. Ma, and Y. Wang, "Polyethylene/aluminum nanocomposites: improvement of dielectric strength by nanoparticle surface modification,” J. Appl. Polym. Sci., vol. 113, no. 6, pp. 3577 3584,2009 .

[27] C. Zou, J. C. Fothergill, and S. W. Rowe, "The effect of water absorption on the dielectric properties of epoxy nanocomposites," IEEE Trans. Dielectr. Electr. Insul., vol. 15, no. 1, pp. 106-117, 2008.

[28] C. Zhang and G. C. Stevens, "The dielectric response of polar and nonpolar nanodielectrics,” IEEE Trans. Dielectr. Electr. Insul., vol. 15, no. 2, pp. 606-617, 2008.

[29] X. Huang, F. Liu, and P. Jiang. "Effect of nanoparticle surface treatment on morphology, electrical and water treeing behavior of LLDPE composites," IEEE Trans. Dielectr. Electr. Insul., vol. 17, no. 6, pp. 16971704, 2010.

[30] K. Y. Lau et al, "On the dielectric response of silica-based polyethylene nanocomposites," J Phys. D Appl. Phys., vol. 46, no. 9, pp. 095303/1095303/9, 2013.

[31] I. L. Hosier et al, "The effects of hydration on the DC breakdown strength of polyethylene composites employing oxide and nitride fillers," IEEE Trans. Dielectr. Electr. Insul. vol. 24, no. 5, pp. 3073-3082, 2017.

[32] I. L. Hosier et al, "Effect of water absorption on dielectric properties of nano-silica/polyethylene composites," Ann. Rep. Conf. Electr. Insul. Dielectr. Phenom. (CEIDP), 2014, pp. 651-654.

[33] M. Roy, J. K. Nelson, and R. K. Maccrone, "Candidate mechanisms controlling the electrical characteristics of silica/XLPE nanodielectrics," J. Mater. Sci., vol. 42, pp. 3789-3799, 2007.

[34] D. Fabiani et al, "Effect of water adsorption on the dielectric properties of polymer nanocomposites," Int. Sym. Electr. Insul. Mater. (ISEIM), 2008, pp. 8-11.

[35] I. L. Hosier et al, "The effects of water on the dielectric properties of silicon-based nanocomposites," IEEE Trans. Nanotechnol., vol. 16, no. 2, pp. 169-179, 2016.

[36] L. Hui, L. S. Schadler, and J. K. Nelson, "The influence of moisture on the electrical properties of crosslinked polyethylene/silica nanocomposites," IEEE Trans. Dielectr. Electr. Insul., vol. 20, no. 2, pp. 641-653, 2013.

[37] C. Zou, J. C. Fothergill, and S. W. Rowe, "A 'water shell' model for the dielectric properties of hydrated silica-filled epoxy nano-composites," IEEE Int. Conf. Solid Dielectr. (ICSD), 2007, pp. 389-392.

[38] M. Praeger et al, "On the effect of functionalizer chain length and water content in polyethylene/silica nanocomposites: Part II - Charge Transport," IEEE Trans. Dielectr. Electr. Insul. vol. 24, no. 4, pp. 2410 2420,2017

[39] K. Y. Lau et al, "Dielectric response of polyethylene nanocomposites: the effect of surface treatment and water absorption," Ann. Rep. Conf. Electr. Insul. Dielectr. Phenom. (CEIDP), 2012, pp. 275-278.

[40] K. Y. Lau et al, "Effects of water on breakdown characteristics of polyethylene composites," J. Electrostat., vol. 96, pp. 119-127, 2018.

[41] I. L. Hosier et al, "The effects of water on the dielectric properties of silicon-based nanocomposites,” IEEE Trans. Nanotechnol., vol. 16, no. 2, pp. 169-179, 2016.
[42] R. Kochetov et al, "Impact of postcuring and water absorption on the dielectric response of epoxy-based composites filled with $\mathrm{MgO}$ nanoparticles," Ann. Rep. Conf. Electr. Insul. Dielectr. Phenom. (CEIDP), 2011, pp. 342-345.

[43] F. Saiz and N. Quirke, "The excess electron in polymer nanocomposites," Phys. Chem. Chem. Phys., vol. 43, pp. 27528-27538, 2018.

[44] L. T. Zhuravlev, "Surface characterization of amorphous silica-a review of work from the former USSR," Colloids Surf. A Physicochem. Eng. Asp., vol. 74, no. 1, pp. 71-90, 1993.

[45] L. T. Zhuravlev, "The surface chemistry of amorphous silica. Zhuravlev model," Colloids Surf. A Physicochem. Eng. Asp., vol. 173, no. 1-3, pp. 1-38, 2000.

[46] L. Peng, "Investigation of the states of water and $\mathrm{OH}$ groups on the surface of silica," Colloids Surf. A Physicochem. Eng. Asp., vol. 334, no. 1-3, pp.112-115, 2009.

[47] D. Qiang et al, "Dielectric properties of epoxy silica and boron nitride nanocomposites and moisture/temperature influences," IET Nanodielectrics, vol. 1, no. 1, pp. 48-59, 2018.

[48] P. Marx et al, "Effect of interfacial polarization and water absorption on the dielectric properties of epoxy nanocomposites," Polymers, vol. 9, no. 6, pp. 195/1-195/16, 2017.

[49] L. A. Dissado and J. C. Fothergill, Electrical Degradation and Breakdown in Polymers, G. C. Stevens, Ed. London: Peter Peregrinus, 1992.

[50] Y. Wang et al, "Single electron states in polyethylene," J. Chem. Phys., vol. 140 , no. 15 , pp. 154902 .

[51] M. Meunier, A. Aslanides, and N. Quirke, "Molecular modeling of electron traps in polymer insulators: chemical defects and impurities," J. Chem. Phys., vol. 115, pp. 2876-2881, 2001.

[52] K. Y. Lau et al "Polyethylene/silica nanocomposites: absorption current and the interpretation of SCLC," J. Phys. D Appl. Phys., vol. 49, pp. 295305/1-295305/12, 2016

[53] S. Virtanen et al, "Electrical conductivity and moisture uptake studies of low density polyethylene octylnanosilica composite," Nordic Insul. Sym. Mater. Comp. Diag., 2017, pp. 1-5.

[54] D. Cubero N. Quirke, "Computer simulations of localized small polarons in amorphous polyethylene", J. Chem. Phys. vol. 120, pp. 7772-7778, 2004.

[55] C. Yeung and A. S. Vaughan, "On the effect of nanoparticle surface chemistry on the electrical characteristics of epoxy-based nanocomposites," Polym (Basel), vol. 8, no. 4, pp. 1-16, 2016.

[56] I. L. Hosier et al, "On the effect of functionalizer chain length and water content in polyethylene/silica nanocomposites: part I - dielectric properties and breakdown strength," IEEE Trans. Dielectr. Electr. Insul., vol. 24, no. 3, pp. 1698-1707, 2017.

[57] K. Y. Lau et al "Polyethylene nanodielectrics: the effect of nanosilica and its surface treatment on electrical breakdown strength," Ann. Rep. Conf. Electr. Insul. Dielectr. Phenom. (CEIDP), 2012, pp. 21-24.

[58] K. Y. Lau et al, "On the space charge and DC breakdown behavior of polyethylene/silica nanocomposites," IEEE Trans. Dielectr. Electr. Insul., vol. 21, no. 1, pp. 340-350, 2014

[59] K. Y. Lau, "Structure and Electrical Properties of Silica-based Polyethylene Nanocomposites," PhD Thesis, University of Southampton, 2013.

[60] M. M. Sung, G. J. Kluth, and R. Maboudian, "Formation of alkylsiloxane self-assembled monolayers on $\mathrm{Si}_{3} \mathrm{~N}_{4}$," J. Vac. Sci. Technol. A, vol. 17, no. 2, pp. 540-544, 2002.

[61] W. Callister and D. Rethwisch, Materials Science and Engineering: An Introduction, John Wiley \& Sons, pp. 975, 2007.

[62] A. Mayabadi, H. M. Pathan, and S. R. Jadkar, "Structural, electrical and photoelectrochemical properties of calcined $\mathrm{SnO}_{2} / \mathrm{TiO}_{2}$ nanocomposite films for solar cell applications," Int. Conf. Technol. Sustain. Dev. (ICTSD), 2015. pp. 5-8.

[63] M. Praeger et al, "The effects of surface hydroxyl groups in polyethylenesilica nanocomposites," IEEE Electr. Insul. Conf. (EIC), 2015, pp. 201204

[64] A. S. Vaughan, "W(h)ither Dielectrics?" IEEE Int. Conf. Dielectr. (ICD), 2016, pp. 1-9.

[65] A. Z. A. Halim, R. Ali, and W. A. W. A. Bakar, " $\mathrm{CO}_{2} / \mathrm{H}_{2}$ methanation over $\mathrm{M}^{*} / \mathrm{Mn} / \mathrm{Fe}-\mathrm{Al}_{2} \mathrm{O}_{3}\left(\mathrm{M}^{*}: \mathrm{Pd}, \mathrm{Rh}\right.$, and $\left.\mathrm{Ru}\right)$ catalysts in natural gas; 
optimization by response surface methodology-central composite design," Clean Technol Environ Policy, vol. 17, no. 3, pp. 627-636, 2015.

[66] A. Opalinska et al, "Size-dependent density of zirconia nanoparticles," Beilstein J. Nanotechnol., vol. 6, no. 1, pp. 27-35, 2015.

[67] N. H. Rahim et al, "Effects of filler calcination on structure and dielectric properties of polyethylene/silica nanocomposites," IEEE Trans. Dielectr. Electr. Insul., vol. 26, no. 1, pp. 284-291, 2019.

[68] C. X. Tian, Y. Yang, and H. Pu, "Effect of calcination temperature on porous titania prepared from industrial titanyl sulfate solution," Appl. Surf. Sci., vol. 257, no. 20, pp. 8391-8395, 2011.

[69] N. Tangchupong et al, "Effect of calcination temperature on characteristics of sulfated zirconia and its application as catalyst for isosynthesis," Fuel Process. Technol., vol. 91, no. 1, pp. 121-126, 2010.

[70] D. Walter, Primary Particles - Agglomerates - Aggregates, in Nanomaterials, D. Forschungsgemeinschaft, Ed. Germany: Wiley-VCH, 2005, pp 9-24.

[71] S. Katheria et al "Effect of calcination temperature on stability and activity of $\mathrm{Ni} / \mathrm{MgAl}_{2} \mathrm{O}_{4}$ catalyst for steam reforming of methane at high pressure condition," Int. J. Hydrogen Energy, vol. 41, no. 32, pp. $14123-$ 14132, 2016

[72] N. H. Rahim et al, "Structure and dielectric properties of polyethylene nanocomposites containing calcined zirconia," IEEE Trans. Dielectr. Electr. Insul., vol. 26, no. 5, pp. 1541-1548, 2019.

[73] D. M. Panaitescu, A. N. Frone, and I. C. Spataru, "Effect of nanosilica on the morphology of polyethylene investigated by AFM," Compos. Sci. Technol., vol. 74, pp. 131-138, 2012.

[74] M. G. Todd and F. G. Shi, "Characterizing the interphase dielectric constant of polymer composite materials: effect of chemical coupling agents," J. Appl. Phys., vol. 94, no. 7, pp. 4551-4557, 2003.

[75] M. Roy et al, "Polymer nanocomposite dielectrics-the role of the interface," IEEE Trans. Dielectr. Electr. Insul., vol. 12, no. 4, pp. 629$643,2005$.

[76] X. Huang et al, "Preparation, microstructure and properties of polyethylene aluminum nanocomposite dielectrics," Compos. Sci. Technol., vol. 68, no. 9, pp. 2134-2140, 2008.

[77] C. Calebrese et al, "A review on the importance of nanocomposite processing to enhance electrical insulation," IEEE Trans. Dielectr. Electr. Insul., vol. 18, no. 4, pp. 938-945, 2011.

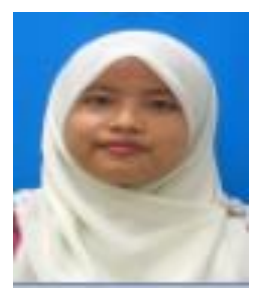

Nor Hidayah Rahim received her B.Eng. in electrical engineering from Universiti Teknologi Malaysia in 2008 and M.Eng. degree in electrical engineering from Universiti Tenaga Nasional, Malaysia in 2012. She recently completed her Ph.D. degree at Universiti Teknologi Malaysia. She is now a Lecturer at Faculty of Electrical Engineering, Universiti Teknikal Malaysia Melaka. Her research interests include high voltage engineering and dielectric materials.

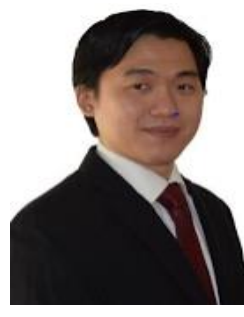

Kwan Yiew Lau (SM'18) received his B.Eng. degree in Electrical Engineering (First Class Honors) and M.Eng. degree in Electrical Power Engineering from Universiti Teknologi Malaysia in 2007 and 2010, respectively. Later in 2013, he received his Ph.D. degree in Electronics and Electrical Engineering from the University of Southampton, UK. He is an Associate Professor at the Institute of High Voltage and High Current, Universiti Teknologi Malaysia. He is also a Chartered Engineer of the Engineering Council UK, a Professional Engineer of the Board of Engineers Malaysia, and the Past Chair of the IEEE DEIS Malaysia Chapter. His research interests include high voltage engineering, dielectric materials and renewable energy systems.

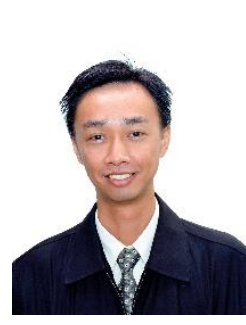

Chee Wei Tan (SM'17) received a B.Eng. degree in Electrical Engineering (First Class Honors) from Universiti Teknologi Malaysia (UTM) in 2003, and a $\mathrm{Ph} . \mathrm{D}$. degree in Electrical Engineering from Imperial College London, UK, in 2008. He is an Associate Professor at Universiti Teknologi Malaysia. He is also a Chartered Engineer of the Engineering Council, UK, a Professional Engineer of the Board of Engineers Malaysia, and the Past Chair of the IEEE PELS Malaysia Chapter. His research interests include the applications of power electronics in renewable/alternative energy systems, control of power electronics and energy management system in microgrids.

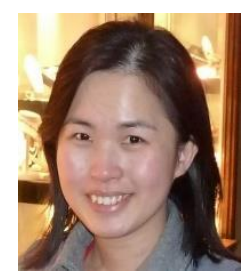

Kuan Yong Ching received her B.Sc. degree in Industrial Chemistry and M.Sc. degree in Chemistry from Universiti Teknologi Malaysia in 2006 and 2008, respectively. She obtained her $\mathrm{PhD}$ degree in Engineering Sciences from the University of Southampton, UK, in 2014. Prior to that, she was a Plating Engineering Development Engineer at Seagate Technology. She is currently a Lecturer at University of Reading Malaysia and a Chartered Chemist of the Royal Society of Chemistry, UK

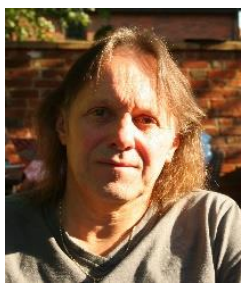

Alun Vaughan (SM'07) has a B.Sc. degree in chemical physics and a Ph.D. degree in polymer physics. After working at the UK's Central Electricity Research Laboratories and The University of Reading, he is now Professor of Dielectric Materials at the University of Southampton. He is a Fellow of the Institute of Physics, a Fellow of the IET and a Senior Member of IEEE. In 2016 he delivered the IEEE DEIS Eric O. Forster Memorial Lecture. 